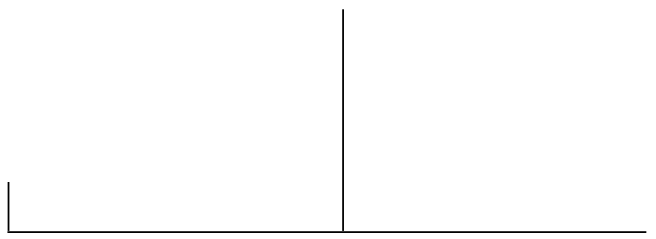

Rev. Latinoam. Psicopat. Fund., São Paulo, v. 13, n. 4, p. 688-694, dezembro 2010

Raij, Tuukka, et al.

Reality of auditory verbal hallucinations

Brain: a journal of neurology, n. 132, p. 2994-3001, 2009.

Atkinson, Joanna et al.

Exploring the Perceptual Characteristics of

Voice-Hallucinations in Deaf People.

Cognitive Neuropsychiatry, v. 12, n. 4, p. 339-361, 2007.

Du Feu, M.

Auditory Hallucinations in Profoundly Deaf Schizophrenic Patients:

a phenomenological analysis.

European Psychiatry, 11 (Supplement 4), p. 296s-297s., 1996.

Lanteri-Laura, G. Signification Clinique et Psychopathologique des Hallucinations. Évolution Psychiatrique: clinique phénomenologique, n. 65 , p. 245-254, 2000.

Atkinson, Joanna

The Perceptual Characteristics of Voice-Hallucinations in Deaf People: insights into the nature of subvocal thought and sensory feedback loops. Schizophrenia Bulletin, v. 32, n. 4, p. 701-708, 2006.

\title{
Surdos, mudos e alucinados
}

Guilherme Gutman

Foi certamente confortante para os seus alunos - e, porque não dizer, uma sensação apaziguadora para toda a posteridade da qual, naturalmente, todos fazemos parte - quando Esquirol (1772-1840) cunhou em seu 
portentoso e decisivo Maladies mentales, de1838, a frase na qual estabeleceu, sobressaindo-se por entre o meio da miscelânea de descrições e de definições que reinavam anárquicas até então, a definição canônica do que se passou a entender como o elemento fundamental de uma experiência alucinatória. Escreveu ele:

Um homem que tenha a convicção íntima de uma sensação naquele instante mesmo percebida, ao passo que na ausência de um objeto exterior capaz de provocar tal sensação, não está na posse de seus sentidos, está em um estado de alucinação: é um visionário. (Esquirol apud Lanteri-Laura, 2000, p. 246)

Os seus alunos - informa Lanteri-Laura (ibid.) - asseveraram todos que Esquirol repetia: “A alucinação é uma percepção sem objeto”. Também Ball (18341893), em suas Leçons sur les maladies mentales (2.ed.), de 1890, recorre à mesma frase presente no tratado de Esquirol para, na sequência, afirmar: "Podemos abreviar essa definição ao dizer que a alucinação é uma percepção sem objeto" (p. 62).

O já mencionado conforto propiciado por esta definição tão precisa para algo tão diversificado quanto podem ser as várias e multifacetadas experiências alucinatórias, não deveria se manter o mesmo após uma releitura atenta da frase de Esquirol; especialmente quando ele a conclui com a afirmação, portadora de alguma ambiguidade, porque levemente contraditória com a intenção vigente de delimitar conceitos: "É um visionário".

A expressão "visionário" deveria doer um pouco nos ouvidos daqueles que, por assim dizer, foram criados na leitura dos compêndios de psiquiatria contemporâneos, supondo ingenuamente que toda a psicopatologia se resumiria a uma espécie de glossário sintomatológico a ser memorizado, e que classificações como a DSM, ou mesmo como a CID, devem tornar-se os seus livros de cabeceira. Por outro lado, essa mesma expressão esquiroliana, otimisticamente, despertará a curiosidade daqueles que intuem a clínica psicopatológica como algo mais do que um mapa de conceitos precisos e de categorias classificatórias bem delimitadas. Estes últimos - alunos inquietos, no melhor sentido do termo - notarão que entre a frase original de Esquirol e a sua posterior docilização sob uma forma sintética, pode estar encoberto um enorme salto; o salto - não seria exagero dizer - de três séculos, ou de três épocas, cada qual representando diferentes modos de compreensão do que seja a loucura.

É que há algo de selvagem na frase do grande mestre francês; e nisso, não se deveria deixar escapar nenhuma das reverberações despertadas pela "selvageria esquiroliana": a sua frase é selvagem porque vem formulada em um texto ainda bruto; selvagem também, porque no ato de sua emissão, pouco antes, portanto, de ser reduzida pelo próprio Esquirol, numa ambivalência anterior à domesticação da qual seria objeto por meio da reiteração operada por seus discípulos, que a cris- 


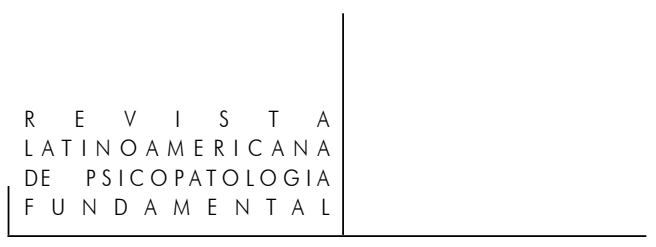

talizaram em uma definição bem acabada. A frase de Esquirol é, afinal, uma representante notável de um momento histórico de apreensão da loucura, no qual ela gradualmente perderá aquilo que eventualmente teria de misterioso ou mágico, para ser exposta à luz forte da ciência psiquiátrica, emergente na virada do século XVIII para o século XIX.

Nos lembra Bercherie (1989), que Esquirol "o mais fiel e o mais ortodoxo dos discípulos de Pinel", pode ter a sua obra sendo pensada como, "toda ela, a aplicação, a ilustração e o aprofundamento das ideias de Pinel" (p. 48). Assim sendo, qualquer peça clínica de Esquirol - e entre elas, naturalmente, a sua definição para alucinação - secunda o gesto clínico inaugural de Pinel (1745-1826), que pode ser sintetizado, naquilo que tem de fundamental, da seguinte forma:

Vamos guardar em mente sobretudo a distância metodológica que Pinel introduziu entre a observação dos fenômenos e a tentativa de apresentar uma teoria explicativa sobre eles, orientando o comportamento do praticante. Foi essa distância fundamental, e a hierarquia que assim se introduziu entre a observação e a explicação, que fundou a clínica e constituiu a ruptura efetuada, com aguda consciência de sua originalidade, por Philippe Pinel. Ele de fato rompeu, assim, com a espécie de unidade sincrética que fazia com que se interpenetrassem, sem limites claros, a forma mórbida e o conceito que a explicava. (Bercherie, 1989, p. 45)

Portanto, o gesto de Pinel na mesma medida em que desembaraça fenômeno e conceito, traz ainda as marcas de uma época anterior àquela que ele próprio inaugura. Seria útil recorrermos, mais uma vez, à periodização proposta por Foucault em sua História da loucura (1961) para reconhecermos, na época inaugurada por Pinel, em fins do século XVIII, o surgimento da psiquiatria como tal, do hospício como local de observação e tratamento e do alienista como aquele que deteria o saber sobre a loucura. Mas como se sabe, as passagens históricas nunca são abruptas e, mesmo muito tempo depois de uma grande mudança estrutural, como a que separa, nos termos propostos no vocabulário foucaultiano, a época clássica da época moderna, pode-se ver brotar, aqui e ali, as marcas de épocas anteriores, em que a loucura não era ainda formatada em "doença mental”, em que a loucura falaria a sua própria língua, ou, pelo menos, não era tornada objeto de tratamento, de exclusão ou, simplesmente, de crítica moral ou riso.

Esquirol, ao definir o sintoma alucinação, semeia o terreno que vinha sendo preparado por Pinel, já caminha com os passos firmes de alienista pelas aleias do jardim das espécies mórbidas e já aponta decidido, a verdade do sintoma com o dedo.

Todavia, há algo de quase literário em seu alucinado personagem visionário. É bem verdade que um visionário, em seu sentido duro, pode ser tão somente alguém que se engana quanto aos próprios sentidos; mas pode ser também alguém que vê ou escuta lá onde a maioria desconhece. É um pouco esse o sentido trá-

Rev. Latinoam. Psicopat. Fund., São Paulo, v. 13, n. 4, p. 688-694, dezembro 2010 
gico, mágico ou misterioso do louco renascentista. Se há mesmo uma camada dessa espécie no visionário de Esquirol, ele poderia, quem sabe, estar em Cervantes ou em Shakespeare; talvez em um quadro de Bosch ou de Pieter Breughel, o velho... Há, enfim, nesse "visionário" uma ressonância trágica, renascentista, que muitos psiquiatras de hoje estranham, desconhecem ou repudiam, tal como alguém que após um passeio por terreno pantanoso, retira das botas, desgostoso, a lama que ficou a elas agarrada; eles, de fato, não gostariam de se incomodar e, já reconfortados pelas novas e velhas verdades adquiridas, estimam que disciplinas como a filosofia ou como a história, permaneçam em algum rincão de periferia, distante de seus domínios.

\section{Surdos que escutam?}

Os Clássicos - entre eles Ball e Cramer (1860-1912) - que Foucault, em sua forma única de periodicizar as formas pelas quais as diferentes épocas abordaram a loucura, chamaria não de "clássicos", mas de "modernos" - interessaram-se vivamente por surdos que relatavam experiências alucinatórias auditivas. Não é difícil imaginar porque, especialmente no caso daqueles surdos de nascença: como seria possível escutar vozes, alguém que jamais tenha escutado som algum; muito menos o som de uma voz?

Inúmeras questões surgem diante do relato dos pacientes surdos: Seriam "vozes verdadeiras" aquilo que os pacientes surdos afirmam ouvir? ${ }^{1}$ Se são de fato "vozes verdadeiras" o que os pacientes surdos escutam, é possível que um estímulo decorrente de algum quadro psicopatológico, do córtex cerebral auditivo - ou de alguma outra área envolvida na circuitaria implicada na audição - seja capaz de produzir vozes em não ouvintes? Que tipo de esclarecimento a investigação das alucinações em surdos poderia trazer à pesquisa etiológica e clínica do fenômeno alucinatório nas psicoses?

Ball (1890) se restringe, embora ressaltando o aspecto curioso do fato, a apontar a existência do fenômeno: “... a surdez, longe de colocar obstáculos a tais fenômenos, parece ser uma das causas predisponentes das mais eficazes. Quase todos os alienados surdos, com efeito, terminam por apresentar alucinações auditivas" (p. 69). Para, em seguida, destacar, sem que se possa saber com que

1. Por exemplo, Du Feu (1996) lança a pergunta de se as alucinações auditivas verdadeiras só seriam possíveis em pacientes que se tornaram surdos após terem adquirido a fala, para, na sequência, afirmar que não: surdos de nascença também relatam a audição de vozes. 
exata intenção, que “... muitas vezes, em tais casos, encontramos na autópsia lesões bem pronunciadas do aparelho auditivo" (p. 70).

Baillarger (1809-1890) traça a diferença entre as alucinações "psico-sensoriais", isto é, escutadas de fora, tais quais pelos órgãos dos sentidos, das "alucinações psíquicas", que seriam aquelas que, sem o componente sensorial, corresponderiam mais àquilo que os pacientes, de algum modo, diriam a si mesmos (Lanteri-Laura, 2000), e que aproximaria tais vivências de pensamentos que são escutados, mais do que experiências propriamente da sensopercepção.

Na mesma linha, Cramer (1896), ao entrevistar dois pacientes surdos que faziam referência a alucinações auditivas, aproxima as vivências alucinatórias a experiências que seriam mais propriamente do pensamento do que da sensopercepção, tais como publicação do pensamento, inserção de pensamento e eco do pensamento.

A importância da inflexão efetuada por Baillarger e por Cramer é a de que, em suas respectivas investigações, o foco é deslocado dos mecanismos da sensopercepção para a relação do sujeito com o seu próprio pensamento. Tal mudança na abordagem do fenômeno alucinatório ganha, entre os clássicos, a sua forma mais apurada (ou, ao menos, mais rica em seus desdobramentos) em Séglas (1856-1939).

Ao estabelecer a distinção entre as "alucinações psicossensoriais verbais" e as "alucinações psicomotoras verbais" (Bercherie, 1989, p. 188-207), Séglas dá um passo fundamental que, como se verá, será a matriz de uma das principais vias de compreensão psicanalítica das experiências alucinatórias auditivas. Enquanto o primeiro tipo de alucinação corresponde ao fenômeno psicopatológico caracterizado pela audição de vozes vindas de fora, o segundo tipo, menos comum, é "o próprio sujeito que profere em voz alta, murmura em voz baixa, ou reproduz da boca para fora aquilo que lhe dizem os seus interlocutores alucinados" (Lanteri-Laura, 2000, p. 250). A importância da introdução das alucinações psicomotoras verbais no vocabulário clínico é dada pelo fato de que esta vivência psicopatológica deixa de ser entendida como um tipo, entre outros, de alucinação auditiva, para ser, na verdade "uma alteração radical da relação verbal do sujeito com ele mesmo, com os outros e com o mundo" (p. 250).

Dito de outra forma, Séglas coloca em cena palavras e frases ou, tão somente, a linguagem. ${ }^{2}$

2. Bercherie cita um trabalho de 1913, em que Séglas revela "em colaboração com seu aluno Barat (...), em certos casos clínicos dos quais eles apresentaram exemplos, a transformação da fala interna (pensamento falado) num estado 'hiperendofásico', depois em alucinação psíquica, e 


\section{Sobre os ombros de Séglas}

É curioso notar que, tendo partido da ênfase sobre a mesma observação clínica - a de que os pacientes que referem alucinações auditivas balbuciam, murmuram ou mussitam aquilo que referem escutar - tenha-se produzido hipóteses tão distintas entre si sobre a natureza do fenômeno alucinatório.

Dentre os artigos pesquisados, Atkinson (2006, 2007), realiza um inventário relativamente extenso e heterogêneo de hipóteses para as alucinações auditivas verbais: ${ }^{3}$

Déficits do sistema perceptual, habilidades meta-representacionais anormais, monitoramento comprometido da fala intencionada, falha do discurso, transtorno de consciência, identificação incorreta da imaginação; enfraquecimento dos processos de armazenamento mnêmico e prejuízo na habilidade de monitoramento da origem da intencionalidade. (2006, p. 703)

Considera a "hipótese de pensamento subvocal" - exatamente uma hipótese explicativa que enfatiza os mecanismos do pensamento e da linguagem, e que se apoia sobre o mencionado dado empírico da articulação vocal na vigência de alucinações - como a mais promissora; tanto em ouvintes quanto em surdos. Segundo essa hipótese, o sujeito reconheceria de modo inadequado "uma fala interna" como oriunda de "um local de controle externo"; nesse sentido, uma alucinação refletiria processos de pensamento que não chegam a ser vocalizados. No que diz respeito às diferenças entre as experiências de surdos e ouvintes, Atkinson $(2006,2007)$ observa que o "componente de feedback sensorial" será obviamente diferente em cada um dos casos, provavelmente implicando qualidades alucinatórias distintas, e que, para além de toda a diversidade alucinatória, seria preciso discutir o que exatamente um surdo, em especial aqueles que já nasceram surdos, entendem por "ouvir vozes".

Neste ponto, seríamos remetidos à polissemia inerente a qualquer termo da linguagem; e, então, dois caminhos se apresentam: ou recorreríamos às regras do

a seguir em alucinação auditiva verbal" (1989, p. 207). Temos nessa citação, um outro exemplo de como Séglas prepara o terreno para uma compreensão das alucinações auditivas na qual a fala começa a ocupar o centro.

3. Há, como era de se esperar, estudos mais localizacionistas, como o de Raij et al. (2009), que, a partir de exames funcionais de imagem, procura mapear a circuitaria envolvida nas alucinações auditivas verbais.

Interessante notar que, para esses autores, a "realidade" das experiências alucinatórias seria comprovada pela presença "real" de disfunções neurológicas. 
uso linguístico - efetuado por ouvintes e por surdos - da expressão “ouvir uma voz", ou suporíamos uma espécie de prevalência estrutural daquilo que é percebido - um segmento de linguagem, poder-se-ia dizer - sobre aquele que percebe.

É nessa última vertente que se insere a perspectiva de Lacan (1966) que, tomando mais uma vez as observações clínicas de Séglas, propõe outra inflexão para a nossa compreensão da experiência alucinatória; mas essa já é uma outra história.

Até a próxima edição!

\section{Outras referências bibliográficas}

BALL, B. Leçons sur les maladies mentales. (2. ed.). Paris: Asselin et Houzeau, 1890.

Bercherie, P. Os fundamentos da clínica: história e estrutura do saber psiquiátrico. Rio de Janeiro: Zahar, 1989.

Cramer, A. (1896). "A propos des hallucinations chez les sourds-muets malades mentaux: avec quelques remarques sur la significations des images motrices de mots dans les hallucinations auditives". In: Analytica: cahiers de recherche du champ freudien. Paris: Navarin, 1982.

Foucault, M. (1961). História da loucura na Idade Clássica. São Paulo: Perspectiva, 1978.

LaCAN, J. (1966). Escritos. Rio de Janeiro: Jorge Zahar, 1998.

\section{Guilherme Gutman}

Psiquiatra e psicanalista; doutor em saúde coletiva pelo Instituto de Medicina Social da Universidade do Estado do Rio de Janeiro - UERJ (Rio de Janeiro, RJ, Brasil); professor adjunto do Departamento de Psicologia da Pontifícia Universidade Católica do Rio de Janeiro - PUCRio (Rio de Janeiro, RJ, Brasil).

Rua Visconde de Pirajá, 595/905 - Ipanema.

22410-003 Rio de Janeiro, RJ, Brasil

Fone: (21) 9106-7009

e-mail: guilhermegutman@gmail.com

Rev. Latinoam. Psicopat. Fund., São Paulo, v. 13, n. 4, p. 688-694, dezembro 2010 